Numerous measures of the comet's position are given in No. 4283 of the Astronomische Nachrichten, whilst in No. 4285 of the same journal M. Geelmuyden gives the positions (1900) and corrections for fifty-two comparison stars, extracted from a series of meridian observations of stars between $65^{\circ}$ and $70^{\circ} \mathrm{N}$. declination, made at the Christiania Observatory during the period 1897-1907.

From Herr Ebell's ephemeris, and Dr. Smart's continuation of it, we give the following abstract:-

$$
\begin{aligned}
& \text { Ephemeris (Greenwich midnight). }
\end{aligned}
$$

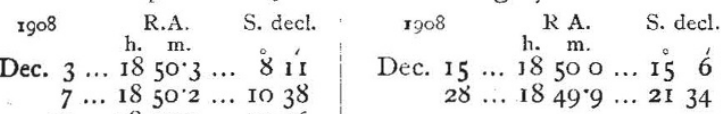

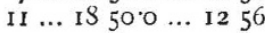

The Change in the Physical Condition of Nova PERSEr.-According to the spectroscopic evidence published by Dr. Hartmann, Nova Persei changed to the nebular condition in the autumn of 1902, whilst later, in 1906, its spectrum was similar to that of the Wolf-Rayet stars.

Prof. Barnard now publishes a series of measures of the star's focus, made with the 40-inch refractor of the Yerkes Observatory between August, I9or, and September, 1903, and a number of notes regarding the Nova's appearance up to September 20 of the present year, which may throw more light on the details of the various changes.

At first the focus was that of an ordinary star, but between 1902 August 29 and October 6 it increased nearly a quarter of an inch, and became the same as that for a nebula; then from November it began to return to the stellar focus, and by the summer of 1903 the focus was essentially stellar. As no further changes were observed the focus measures were then discontinued.

Prof. Barnard also made focal measures of seven WolfRayet Stars, and found that the focus gencrally appears to be shorter than for an ordinary star, whilst the stars are yellowish, and in some cases appear to be surrounded by a glow or halo (Astronomische Nachrichten, No. 4285 , p. 20I).

Refraction due to Juriter's Atmosphere.-In a recent note in the Astronomische Nachrichten (No. 4272), M. Chevalier published an account of an observed occultation of a star by Jupiter, and directed special attention to the fact, without offering any explanation of the phenomenon, that the star did not disappear at the point of the planet's limb to which its apparent motion, in regard to the planet, was directed some minutes before; that is to say, the star's apparent path was deflected immediately before immersion took place. In No. 4285 of the same journal (November 24, p. 206) M. E. Esclangon offers an explanation of the phenomenon. It is that the apparent deflection is caused by the horizontal refraction at the surface of Jupiter, and he finds that the observed direction and amount of the deflection are in good accordance with the theoretical value for the refraction. Although the disappearance of the star was apparently instantaneous, a diminution of light, such as might be caused by the absorption due to the planet's atmosphere, was observed.

Observations of the Zodiacal Light.-At the suggestion of Prof. Campbell, Mr. E. A. Fath made a number of observations, at the Lick Observatory, during the past summer, in order to determine, if possible, the true nature of a faint light which has for years been observed along the northern horizon from Mount Hamilton during the summer.

The observations show that it is probably due neither to twilight nor the aurora borealis-although the strong aurora line at $\lambda 557 \mathrm{I}$ was observed spectroscopically both within and without the illuminated area-but to the zodiacal light. Details of the observations are given at length, and they show that the northern boundary of the light reached an altitude of $46^{\circ}$ (Lick Observatory Bulletin, No. 142 ).

L'Annuaire du Bureau des Longitudes.-This annuaire, for 1909, is now published, and contains the usual very complete series of tables for use in astronomical, meteorological, geographical, and general scientific work.
The article "Spectres des Étoiles," which used to be written by the late $\mathbf{M}$. Cornu, is replaced by a most interesting résumé of stellar spectroscopy prepared by M. A. de Gramont. This will be found very useful for reference, as it contains a brief account of the various stellar classifications of Secchi, Pickering, Lockyer, and others, with notes on their correlation. The annuaire is published by Gauthier-Villars, Paris, at r.50 francs.

\section{THE CORRELATION OF THE TEACHING OF MATHEMATICS AND SCIENCE.}

$\mathrm{I}^{\mathrm{T}}$ is known that for some time past the Mathematical Association has been arranging for a joint committee with the Association of Public Schools Science Masters to report on the teaching of mathematics in connection with science. In furtherance of the same object a conference was held at the Regent Street Polytechnic on Saturday, November 28, between the Mathematical Association and the Federated Association of London Non-primary Teachers, the main feature being an address by Prof. John Perry, F.R.S., bearing the title of this article.

Prof. Perry said that a certain senior wrangler had objected to the name mathematician being applied to a mathematical physicist, and he therefore confined the term to those who were enlarging the scope of pure mathematics. Mathematicians, instead of being able to devote themselves to research, were forced to teach elementary classes; they also took part in examinations, and sometimes wrote treatises on hydrostatics, which were really books on integral calculus with such terms as pressure and depth.

The consequence was that too much attention was given to so-called rigorous proofs, and boys wasted much time in learning such subjects as deductive geometry, artificial devices for solution of triangles, and drudgery with algebraic symbols. The conditions of one examination at one British university had led to the creation of 90 per cent. of elementary algebra and trigonometry in Great Britain, this unnecessary 90 per cent. being as complex and tricky as it was possible to make it. Until this sort of thing was done away with the marriage of mathematics and science was like that of December and May. $\mathrm{He}$ alluded to the arbitrary division of examinations into water-tight compartments headed "Algebra," "Trigonometry," "Mechanics." He maintained that students ought to learn to use logarithms, and even Fourier's theorem, long before they could prove their methods. $\mathrm{He}$ thought school lessons should be on the type of Sandford and Merton and Mr. Barlow. There should be no division into subjects. Boys should learn to weigh and to measure. to calculate and to find things out for themselves. The form-masters should be all-round men, not specialists There should be one teacher to every ten boys, and that teacher should be well paid. Every master should be responsible for English composition. If a boy wrote a description of anything he had done in a laboratory or elsewhere, it should be an exercise in English. He referred to the methods of teaching adopted by Dr. Andrews, of carbonic acid fame. Continuing, it astonished him to see how little comprehension there was of the proposals of the British Association committees. They recommended some work with graphs on squared paper, and some teachers did nothing but graphs, and there were dozens of school-books to help on the craze. The surprising thing was that many teachers seemed to have no individuality, no originality, nor even the power to think for themselves at all. He asked that the changes that were taking place should go on unchecked. Mistakes would be made at first, and it was their duty to make the public believe in the necessity for better paid teachers in order to attract really able men.

Prof. Bryan, who occupied the chair, thought Prof. Perry attached too much importance to the distinction which an idealist drew between a mathematician and a mathematical physicist. Consequently, his address tended to give the impression that the man who did research in pure mathematics was at the root of all the evil. In Prof. Bryan's opinion the fault rather lav with those whose only idea of research consisted in inventing 
" pretty" questions unsuitable for a three-hours' examination paper. At Bangor $\mathrm{Mr}$. Lloyd George had directed attention to the need of explorers who should survey the unknown regions of science. This need was urgently felt in mathematics, both pure and applied. Thus the theory of groups was a newly explored territory which might in time become a field of wealth in the hands of colonists like Prof. Perry. The true explorer would never stand in the way of progress. It was the man who thought he had done everything when he had competed in a walking race over the measured mile of a syllabus who never became an explorer, and never produced explorers. No man who relied only on his powers of walking would ever become an explorer. We required men to be carried over the greater part of the distance by the fastest means of locomotion at our disposal to bring them to the forefront of the unknown territory, and this was in effect what Prof. Perry wished to do. The research mathematician was in reality assisting, not hindering, progress. He had exposed the futility of elementary deductive geometry by raising the foundations of geometry to the level of a very difficult and advanced subject of post-graduate study. As for Fourier's theorem, modern researches had made the proof of that theorem a subject involving years of study, thus rendering it impossible for the science man to do more than study its applications. As for examinations, Prof. Bryan was thankful he had not been debarred from conducting them, as this work had afforded him most valuable experiences, and, referring to Prof. Perry's remarks on the solution of triangles, he gave a striking illustration of the cumbersome methods adopted by examinees in finding the area of a right-angled triangle by the unnecessary use of formulæ. There was far too much teaching and far too little learning. Prof. Perry lamented the lack of individuality on the part of teachers, and at the same time condemned the specialist teacher. Prof. Bryan, on the other hand, thought that the cause was that the teachers were not sufficient specialists to develop original ideas, and that an all-round man who was put on to teach mathematics, Latin, history, geography, Welsh, and chemistry could never (except in rare instances) get beyond blindly following the text-book or the examination syllabus.

Mr. Godfrey next spoke. He said that subjects such as mechanics, hydrostatics, and optics were, as a rule, taught in one way by the mathematical master and in another by the science master. He would throw the whole teaching of these subjects, both theoretical and practical, on the mathematical master. There was no educator so good as responsibility. The mathematical master would benefit by having the experimental work thrown on his shoulders; the science master would have more time for other work.

The reference to optics might well have been dwelt on at greater length. There is no better exercise in constructive geometry than the construction of reflected and refracted rays, caustics, and images, and the subject is capable of exact experimental verification, thus differing from the study of the motion of impossible particles on equally impossible smooth curves. Mr. Godfrey further pointed out that the clock sums and problems on filling baths had plenty of counterparts in the form of questions on graphs.

Mr. Jackson quoted Emerson's view that education was what remained when everything learnt at school was forgotten. There was no one panacea for inaccuracy. He recommended for graphs the use of a board with invisible squares scratched on it, identical in principle with the boards used by lightning caricaturists in music halls. $\mathrm{He}$ referred to the great French logarithmic tables, the computation of which was done by hairdressers who had been thrown out of work by the Revolution. We wanted to make boys believe that mathematics was a useful element in daily life, and not a punishment for their sins.

Prof. Alfred Lodge thought that in the higher forms boys taking mathematics might dispense with experimental work. He suggested that lists might be drawn up of experiments suitable for illustrating mathematical principles, and, conversely, that in science text-books each chapter might be prefaced by a list of mathematical formulæ.

Mr. W. J. Dobbs put in a plea for deductive geometry, which, he contended, was realiy a branch of experimental physics involving properties of matter. He referred to the value of mechanics in teaching trigonometry. He pleaded for the use of simple, inexpensive home-made apparatus, and contended that a great deal of money now spent on costly apparatus should be given to the teachers. $\mathrm{Mr}$. Tuckey pointed out that two subiects taught by the same teacher were not necessarily correlated.

Prof. Armstrong suggested that Prof. Perry would have to tell teachers absolutely what they ought to do. People would be glad to learn, but they were not at present competent to understand his methods. Mathematicians must take off their coats and use their hands. The majority of pupils should not be trained from the scholarship point of view. He asked if there was any particular value in any educational subject.

After Mr. Nunn had spoken the latter question was again raised by the chairman, and Prof. Perry emphasised the necessity of differentiating between subjects which were useful in themselves and subjects which were educationally useful. Every child should be fond of reading and should be good at computation. $\mathrm{He}$ should have an elementary knowledge of science, and be able to express his ideas clearly in English. Lord Roberts's statements regarding the incompetence of men from the public schools when on service during the South African war were quoted. Prof. Bryan urged those present of the necessity of fighting that practical mathematics should receive its proper importance in the training of the working citizen, and that it should not be ousted by subjects the study of which had once formed the luxury and pleasure of the now vanishing English middle classes, but had only given rise to sadness and disappointment when these classes had been forced to earn their daily bread in the world at large. A vote of thanks was finally proposed by $\mathrm{Mr}$. Siddons, who gave illustrations of the reforms that had actually taken place in recent years largely at the instigation of Prof. Perry.

\section{SCIENTIFIC INVESTIGATIONS OF} FISHERIES. ${ }^{1}$

TO the scientific inquirer the issue of these reports is, on the one hand, interesting for statistical and other proofs of the actual condition of the British sea-fisheries, and, on the other, for a statement of the views of impartial men-especially concerning the measures, if necessary, to be adopted for the preservation and improvement of the fisheries.

In the annual report of the English fisheries for 1906 it is gratifying to find that the quantity landed exceeded that of any previous year, and, if corroboration were necessary, the report of the Scotch Board for that year, and also for 1907 tell the same tale. It is further satisfactory to observe that by the methods now adopted the report is more nearly brought into line with modern requirements, and reflects credit on the Board and its staff. It may be pointed out, however, that the terms "demersal" and "pelagic" as applied to the food-fishes (and very suitable for their ova) are not free from misinterpretation even by fisheries' authorities, and it may be that the old terms "round" and "flat" white fishes and "skate," as distinguished from " herrings, mackerel, pilchards, sprats and anchovies," would prove as usefuI and at the same time be in accordance with the classification adopted by the Scotch Board. It is suggestive, again, that in the south dabs are included in the "decreasing" flat fishes, whereas the Scotch Board lately considered that this abundant form was usurping the areas of the more valuable plaice. The growing scarcit of marketable plaice is anxiously recorded, yet it is a complaint of very old date, and it has not been shown that the numbers of very small plaice show any diminution. The statistics of the average catch of this fish per day during the years $1903-6$ must be cautiously accepted, since there

1 (r) Annual Report of the Board or Agriculture and Fisheries under the Acts Relating to Sea-fisheries for the Year roof (1908).

(2) Report of Research-work of the Same Board on the Plaice Fisheries of the North Sea, 1905-6 (1908).

(3) Report of the Committee appointed by Treasury-Minute to inquire nto the Scientific and Statistical Investigat ons $n>w$ being carried on in Relation to the Fishing Industry of the Uni ed Kingdom.

NO. 2O10. VOL. 79] 